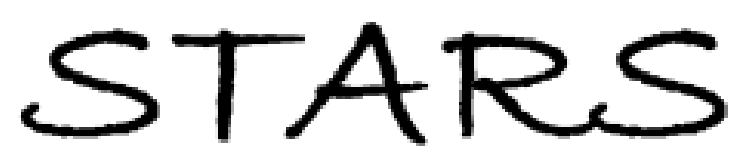

University of Central Florida

STARS

$10-29-2013$

\title{
Examining Key Drivers of Customer Delight in a Hotel Experience: A Cross-Cultural Perspective
}

\author{
Edwin Torres \\ University of Central Florida, edwin.torres@ucf.edu \\ Xiaoxiao Fu \\ Xinran Lehto
}

Part of the Hospitality Administration and Management Commons, and the Tourism and Travel Commons

Find similar works at: https://stars.library.ucf.edu/rosenscholar

University of Central Florida Libraries http://library.ucf.edu

This Paper is brought to you for free and open access by the Rosen College of Hospitality Management at STARS. It has been accepted for inclusion in Rosen Faculty Scholarship and Creative Works by an authorized administrator of STARS. For more information, please contact STARS@ucf.edu.

\section{Original Citation}

Torres, E., Fu, X., \& Lehto, X. (2014). Examining the key drivers of customer delight in a hotel experience: A cross-cultural perspective. International Journal of Hospitality Management, 36, 255-262.

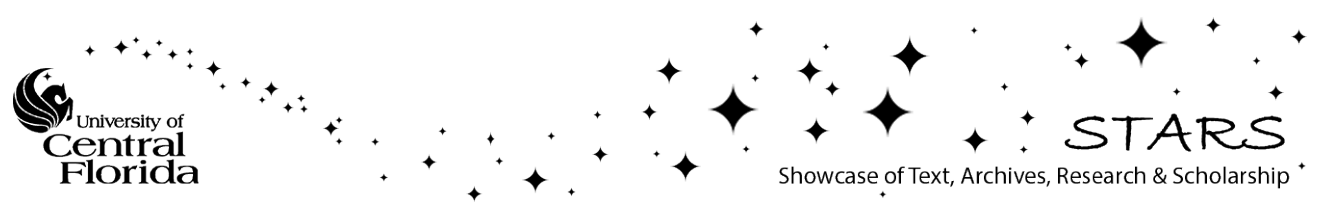




\title{
Examining key drivers of customer delight in a hotel experience: \\ A cross-cultural perspective
}

\begin{abstract}
Welcoming all guests is the calling shared by those who work in the hotel industry. Everyday hoteliers strive to provide a service of excellence to all of those who visit. This can be somewhat of a complex endeavor, as hotels receive guests from different nationalities and cultures. Previous research in the area of customer delight has revealed some of the factors that define and drive the customer delight experience. Despite the emerging literature on the subject, the question remains: are guest from different cultures likely to be delighted by different things? In the present study, the researchers conducted extensive semi-structured interviews $(n=228)$ with guests from different nationalities visiting the Central Florida area. The guests interviewed came predominantly from the United States, Brazil, Germany, and Canada. Using a process of content analysis, the researchers analyzed the drivers of customer delight and concluded that while some universal service elements exists, guests from different cultures can also be delighted by different services and amenities.
\end{abstract}

Keywords: Customer delight, customer satisfaction, culture, hotels 


\section{Introduction}

Marketers in the hotel industry strive to perform up to customers' expectation and deliver an exceptional service. Therefore, they constantly seek to gain insights on service quality through investigation on customers' experience, such as on what customers like and what they dislike (Crotts et al., 2008). Nevertheless, a customers' experience is an experiential product that involves the intricacy and resiliency of subjectivity. Furthermore, the task of creating a great experience is even more daunting at a global stage as many hotels enter foreign markets and find themselves in whole new cultures. Consequently, understanding what constitutes a valuable customer experience becomes a question to be tackled for firms seeking to be successful in the global market.

Customer satisfaction has been believed to be the ultimate goal for service industry. However, some research challenges the previously-held assumptions that customer satisfaction leads to loyalty (Skogland \& Siguaw, 2004). Moreover, existing research also suggests that merely satisfied customer is not necessarily a loyal nor committed (e.g. Voss et al., 2008). Facing the challenge, researchers have attempted to prescribe solutions. Some scholars turned to the notion of customer experience which is holistic in nature and may include "every point of contact at which the customer interacts with the business, product, or service" (Grewal, Levy, \& Kumar, 2009, p.1). Hosany and Whitman (2010) proposed that experiences should be memorable, that is, the customer must be able to retrieve them from their memory; and be distinctive. Similarly, Pine and Gilmore (1999) argued that emotionally engaged customers are more likely to repurchase and recommend to others; in order to have such effects, businesses must orchestrate a memorable experience for their customers. It has also been found that, across 
the entire spectrum of service experience, the peak moments largely shape customers' retrospective evaluation (Varey and Kahneman, 1992).

The existing body of service literature demonstrates a rather lopsided phenomenon. Consequently, a vast amount of research exists on the topic of service recovery, while a much smaller stream of research exists on positive service experiences. Emphasizing both aspects of emotional attachment and peak experience, the concept of customer delight has accordingly become a topic of interest (Keinningham, Godard, Vavra, \& Laci, 1999; Kumar, Olshavsky, \& King 2001, Finn, 2005; Torres \& Kline, 2006; Magnini, Crotts, \& Zehrer, 2011; Wang, 2011). However, even within the realm of customer delight, little attention has been paid to the crosscultural context, which is increasingly important to today's service environment. In effect, it is strategic for firms to look at the other end of the continuum of customer responses and examine the critical aspects of services that they do right in addition to what they do wrong.

Service failure will inevitably occur due to resource constraints and reasons to service failure could be consistently inconsistent for each encounter. Yet a delightful service that impresses customers is unlikely to be easily replicated by competitors (Crotts et al., 2008). In other words, customer delight can be a strategic resource in competitiveness. Therefore, to maintain and enforce on areas that are already warmly embraced by customers is more strategically sound. In light of the present knowledge on this subject, the present study explored customer delight in a lodging experience. The topic of customer service and customer experience is highly relevant in the hotel industry and therefore warrants further empirical study. The objective of this study was to examine the phenomenon of customer delight from a crosscultural perspective. Specifically, it aims to explore the factors that drive a delightful experience and to uncover the difference existing across various travelers. 


\section{Theory}

\subsection{What is customer delight?}

Customer delight has been defined from three different perspectives in the current literature. One definition stresses the confirmation-disconfirmation paradigm. The next group of research stresses the emotional components. Finally, the last school of thought emphasizes human needs. Stressing the disconfirmation perspective, Patterson (1997) proposed that customer delight is where the experience goes beyond satisfaction and involves a pleasurable experience for the guest. Keinningham, et.al. (1999) proposed that customers have a certain zone of tolerance and that performing beyond the upper thresholds of such zone would generate customer delight.

Another approach to defining customer delight is to take an affect-based approach. As an example of such research, Kumar, Olshavsky, and King (2001) proposed that customer delight is composed of the emotions of joy, thrill, and exhilaration. Finn (2005) defined customer delight as an emotional response which results from surprising and positive levels of performance. Finally, Schneider and Bowen (1999) proposed that customer delight is a function of the satisfaction of three human needs: security, justice, and self-esteem.

Admittedly, delight and satisfaction share common characteristics. According to the expectancy-disconfirmation model (Oliver, 1980), customers are expected to compare prepurchase expectation with the actual experience of product or service. If perceived performance fails expectation, dissatisfaction or outrage will occur. If perceived service quality exceeds expectation, then positive responses such as satisfaction or delight will arouse. Therefore, delight and satisfaction are unified by their nature as positive emotions. 
The two constructs, however, are separated by antecedent condition and magnitude. Delight entails a pleasant surprise which satisfaction lacks. It's noted that the emotional state of being delightful is a blend of happiness and surprise (Kumar et al., 2001; Berman, 2005). This is in keeping with Oliver et al. (1997) proposition that surprise acts as an antecedent for delight to occur. A recent study analyzed Tripadvisor blog postings and found that surprise is an essential component of the delight construct. In addition, the surprise component was found to be strongly associated with customer loyalty (Crotts \& Magnini, 2010). There are other reasons why surprise might be an important element in customer delight. First, surprise may trigger emotional arousal, which has been proven to have a major effect on customer delight (Bowden \& Dagger, 2011). Second, according to Wang (2011) "customers are often surprised under disconfirmation situations." (pp. 150).

Compared to satisfaction, delight also stresses the state of emotional attachment and is more strongly associated with customer loyalty, positive word of mouth, and repeat purchase intent (Torres \& Kline, 2006). Ekinci, Dawnes, and Massey (2008) proposed that customer delight is highly individualized based on needs and personality. On a continuum, Berman (2005) proposed four stages to measure post-purchase customer responses. Specifically, they are outrage/pain, dissatisfaction, satisfaction, and delight. As customer emotions moves through the continuum from negative to positive, customer loyalty is expected to ascend.

In order to gain deeper knowledge into the concept of customer delight, Ma et al. (2013) adopted a model based on the Cognitive Appraisal Theory (CAT). This process-based approach posits that emotions (and delight in particular) are elicited by various factors including the customer's knowledge, goal congruency, agency, certainty/ novelty, and goal relevance. These factors will exert influence over an individual's appraisal of a situation, and thus lead to the 
arousal of positive affect, resulting in the more specific emotion of delight. According to Ma et al. (2013), the state of delight can be elicited "when tourists appraise their theme park experience either as unexpected, or as important to their personal well-being or special needs, or as in their interest, or as highly goal congruent" (pp. 373).

In sum, existing literature commonly addressed that the construct of delight bears two characteristics: a) Delight occurs as a result of memorable, positive reproducible events. As opposed to satisfaction, delight lingers for a longer period of time, and: b) Delight is more strongly associated with customer loyalty and intent to repeat purchase. Compared to merely satisfied customers, delighted customers tend to be more loyal and more likely to be retained.

\subsection{Key drivers of customer delight}

Key drivers of customer delight have been defined as service attributes that contribute to a delightful experience (Crotts, 2008). Such factors have major impact on customer evaluation and behavior which include satisfaction and repeat purchase intention. Some customer delight drivers might be context-specific rather than universal. From the perspective of customer experience management, it is strategically meaningful to explore what these key drivers are as evaluation with different components of an experience may have remarkably different impacts on the overall evaluation. In a guest's mind, one under-performed area may not be the dealbreaker to the lodging experience. Rather, the entire experience can be spoiled if the perceived key areas do not perform well. Despite the association of delight drivers with customer

experience, very few studies have actually dedicated to empirically examine this phenomenon and no study to the author's knowledge has explored it in a hotel setting.

Among existing empirical evidence, the study by Crotts et al. (2008) investigated key delight drivers in the context of a food and wine festival. Using data collected from 310 
participants, the authors identified "diversity of wines and food tasting" and "quality of the food samples" as two major factors that contribute to participants' delight. Also noteworthy is that, although respondents mentioned negative impressions of the festival such as "lack of seating" and "too crowded", they still rated the overall experience as positive and demonstrated revisit intention. Thus, delight generated from key driver areas is proven to be persuasive enough to counteract negative feelings and dictate the overall evaluation. Torres and Kline (2013) conducted content analysis of letters of guest feedback. As part of their results, they present a typology for customer delight. Accordingly, the following themes were presented: charismatic delight (associated with employee friendliness personality), fulfillment delight (associated with the fulfillment of higher-level needs such as that of self-esteem), problem resolution delight (resulting from the effective solution of a guest problem, especially when it was not the hotel's responsibility), professional delight (resulting from employee professionalism), and comparative delight (emerging from the realization that a hotel is superior to that of competitors).

Seeking a deeper understanding of the experience economy, Hosany and Witham (2010) studied the experience of cruise travelers from three different nationalities. They discovered that esthetics had the highest impact on the guests' appraisal of the cruise experience, followed by the dimension of entertainment, and escapism. Their study proposed that pleasant experiences will positively impact satisfaction, and this in turn will affect a traveler's intention to spread positive word-of-mouth.

\subsection{The influence of culture}

Defined as "complex whole which includes knowledge, beliefs, art, morals, law, customs, and any other capabilities and habits acquired by man as a member of society" (Tylor, 1924), culture serves as time-tested guidelines on behavior patterns common to the society (Sheth et al., 
1991). In delineating how culture prescribes individual behavior, sociologist Bourdieu (1977) introduced the Theory of Practice to explicate the relationship among Culture-DispositionsPractices. Specifically, culture dictates dispositions, which include beliefs, habits and values well-established and widely-shared within a society. Dispositions in turn influence practices, which are behaviors of everyday life. Drawing on Bourdieu's theory, it's likely that people originating from different cultural backgrounds judge the same experience from markedly different perspectives. In turn, evaluation results may also differ on saliency. In the context of service industry, certain customer judgment and interpretations may be universal and others could be more culture-specific in nature.

One of the most important theories regarding the role of national culture in management comes from Hofstede (1993). In particular, his work sent shock waves in the business field, as he challenged the widespread applicability of management theories. He argued for the scholarly and managerial attention to cross-cultural understanding, for "there is something in all countries called 'management', but its meaning differs to a larger or smaller extent from one country to another, and it takes considerable historical and cultural insight into local conditions to understand its processes, philosophies, and problems" (Hofstede, 1993, p. 89). In order to clearly delineate the cultural differences, Hofstede (1993) proposed five dimensions, including power distance, individualism/ collectivism, masculinity/ femininity, uncertainty avoidance, and longterm/short-term orientation, which have become a well-cited framework for many studies on service experience.

To understand the impact of culture in customer satisfaction, Crotts and Erdmann (2000) studied international tourists after their visit to the United States, utilizing the masculinity/ femininity dimension developed by Hofstede (1993). High masculinity cultures tend to 
emphasize competition and assertiveness, whereas cultures of high femininity tend to stress concern for other and interpersonal relations. The researchers discovered that guests from high masculinity cultures were more likely to be critical of various aspects of their experience such as airport facilities. In contrast, those from national cultures with low masculinity (i.e. high femininity) tended to offer more positive evaluations of their experience. In terms of loyalty, travelers from high masculinity cultures displayed greater defector tendencies, while those who traveled from high femininity cultures were more likely to be loyal (Crotts \& Erdmann, 2000).

Another study by Tsaur et al. (2005) examined the service quality dimensions of SERVQUAL (Parasuraman, et al., 1988) in relation to the cross-cultural impact. In the dimensions of tangibles, reliability, and empathy, tourists from the English heritage cultures tended to perceive better service quality, more so than their Asian and other European counterparts, while in the dimensions of responsiveness and assurance, the Anglo-Saxon group perceived better quality than the Asians. The effect of cultural norm on both the expectations and the perceptions of service delivered has also been similarly noted in the study by Weiermiar (2000). As further evidence of the role of culture in shaping the perceptions of service quality and customer satisfaction, Laroche et al. (2004) performed a series of experiments in dental offices, with a sample of American, Canadian, and Japanese guests. It was discovered that Japanese guests were more conservative about the evaluations of superior service; in other words, they rated superior service lower than their American and Canadian counterparts. Nevertheless, they were also more forgiving when service performance was lower.

The study by Luna and Gupta (2001) proposed a conceptual model of culture and consumer behavior. While culture impacts consumer behavior, the latter may also shape the former as consumer behavior may eventually come to be regarded as desirable or otherwise 
rejected by the group. During the consumptive experience, the actions of the marketers can help to either reinforce current cultural values or suggest new ones. Similar to the general propositions in the service literature, delight has been postulated as an emotionally charged consumer reaction which can also be culturally specific. As Kitayama, Markus, and Kurokawa (2010) posited, the seemingly basic, common types of human feelings is in fact a result of "a culture-specific package of subjective contents, behavioral and interpersonal antecedents and consequences, and many physiological concomitants" (p. 120); delight is no exception. For example, the needs-based model by Schneider and Bowen (1999) posits that customer delight and outrage can originate from the basic human needs of justice, security, and esteem. If the three needs are pampered, delightful feelings will occur as a result. Conversely, mishandling of such basic needs will lead to a bad experience. Like other human needs, the constructs of justice, security, and esteem are subject to cultural interpretations and may be felt differently in a foreign environment. In the same vein, a service episode that delights a guest from the one culture might not gratify a guest from another to the same extent.

\subsection{The impact of customer delight}

For years, customer satisfaction has been used as the benchmark of success in managing customer relationships. In recent years, customer delight has been studied as the new standard of managing guest relations. Some researchers have proposed that as the level of satisfaction increases, loyalty among customers increases. In light of this, it has been revealed that very satisfied customers were more likely to be loyal than customers who said they were satisfied (Kumar, et al., 2001). Customer delight has also been found to have a stronger impact on affective loyalty when compared to customer satisfaction (Kim, 2011). Finn (2005) argued that previous studies that sought to understand the relationship between satisfaction and loyalty have 
produced mixed results due to the possibility of a non-linear relationship. He proposed that at extreme levels of satisfaction or arguably delight, the relationship to loyalty is potentially stronger (Finn, 2005).

If customer delight improves customer loyalty, then business results should follow. In fact, Patterson (1997) argued that companies with loyal customers can succeed with prices $7 \%$ higher than their competitors. Nevertheless, providing excellent service is not always cheap. Rust and Oliver (2000) acknowledged the importance of customer delight, but also realized the potential costs. Accordingly, they created a mathematical model has been proposed to explain the circumstances by which delighting customers may result in more profit for a firm (Rust and Oliver, 2000). Given the existing literature in the field of customer delight and seeking to expand the body of work, the following research questions are proposed:

- Are there similarities and differences in the elements that trigger delight across cultures?

- What can service providers to provide an experience that would delight all their guests?

\section{Methods}

In order to investigate the key drivers of customer delight, the researchers conducted interviews with hotel guests. More specifically, the present research combined qualitative openended questions with close-ended questions that can be quantified. Before conducting interviews, the researchers developed a protocol based on the instrument developed by Crotts, et al. (2007), which used four questions to capture the key drivers of customer delight. They are Q1: What are the three things you enjoyed most about your visit? Q2: What are the three things you enjoyed 
least about your visit? Q3: I thoroughly enjoyed my visit (on a scale from "strongly disagree" to "strongly agree") and Q4: The probability that I will visit again next/year is (on a scale from $0 \%$ to $100 \%)$. In addition to these questions, the researchers also asked questions regarding some of the customer delight typology identified by Torres and Kline (2013), namely friendliness, professionalism, fulfillment of esteem needs, and problem resolution. The full interview protocol can be seen in Appendix A. It is noteworthy to state that the instrument is not an exact replication of the methodology used by Crotts et al. (2007); rather, it draws key questions from the study with regards to customer delight.

The present research sought to obtain descriptions of factors that contribute to a delightful experience. The researcher's intent was not to give a sweeping generalization of the difference between guests of different cultures, but to provide insights into the phenomenon under investigation. The interviews were conducted in an upscale hotel in the Central Florida area during a period starting on January 2013 and ending on March 2013. Guests of different cultures were approached for qualitative interviews. A total of 228 interviews were conducted during this period (for more results on respondent demographics, please see the results section). At this point, saturation point was reached. Prior to the interviews the researchers obtained permission from the hotel's management as well as the university's Internal Review Board (IRB).

The data was recorded in the form of written notes and shortly thereafter transcribed. The interview transcripts were coded independently by three trained coders. The first rater coded all 240 letters. The second and third raters' coding assignment was as follows: a) all the European letters, b) all the Latin American letters, c) all the Canadian letters, d) a random sample of the American letters (a sample of the U.S. letters was used due to their larger size). All raters 
had expertise in the area of customer delight. A codebook (see Appendix B) was developed as a result. Following the development of the codebook, letters were coded using a process of content analysis. According to Iverson (2000, pp. 32), content analysis has many advantages, among which its primary strength lies in its ability to analyze and interpret people's account of an event without taking away its power or eloquence. Usually involving multiple steps, content analysis is a process which starts with the development of categories and then follows with the coding of the content and ends with narrative demonstration or statistical analysis of the data. This method is considered to be especially suitable for enhancing knowledge of a real-world phenomenon that has not received deserved attention.

The data analysis followed both an inductive and a deductive process. The codebook was initially developed based on the review of related literature. For example, Torres and Kline (2013) in their research developed a codebook for content analysis. This study used a modified version of such codebook. Additionally, as the coders read the letters; new themes emerged. Consequently, the codebook was modified to contain all of the relevant themes from the letters of feedback, as well as the information from the relevant literature. In light of this, the process both utilized information from the literature and also utilized the transcripts themselves to draw additional themes and patterns. The codebook can be found in Appendix B.

Following the independent coding of all three raters, an assessment of reliability took place. Inter-rater reliability was calculated using the percentage of agreements and kappa value. Based on the initial coding, the raters agreed on $82 \%$ of all the codes during the first round of coding. Then all three reviewers met and analyzed the areas of agreement and disagreement, ultimately making final coding decisions. During the second round of coding, raters agreed on 90.1\% of coding instances. The assessment of reliability showed substantial agreement among 
the raters, as demonstrated by a kappa value of .727. In other words, the study attained an acceptable level of agreement with an acceptable kappa value.

\section{Results}

\subsection{Respondent Profile}

During the course of the present research, guests were interviewed in the public areas of an upscale hotel in the central Florida area. From the total amount of letters $(n=228), 140$ respondents were from the United States; 38 were from Northern Europe, namely Germany; 19 were from Latin America, namely Brazil; 19 were from Canadians, and 12 were from other countries. A total of $52 \%$ of guests were male, and $48 \%$ were female. The interview protocol (Appendix A) inquired among other things, about a guest's delightful experiences. If the guest did not have a delightful experience at the research hotel, they were asked to recall a delightful experience in another hotel. Among the interviewed guests, 58\% commented about a delightful experience in the study hotel, whereas the remaining $42 \%$ conveyed a story about other hotels they had previously experienced. Among those who recalled their experience at the study hotel, $68 \%$ stated that it was their first stay in property, $17 \%$ indicated it was their $2^{\text {nd }}-5^{\text {th }}$ time, and $14 \%$ had stayed at the hotel for 6 or more times.

\subsection{Content Analysis Results}

\subsection{American Guests}

The researchers analyzed the interview transcripts using the codebook (Appendix B).

During the coding process, it was apparent that guest from different countries exhibited different patterns of preference in terms of the desired amenities, style of service, and importance assigned to various divisions within the hotel. The first set of interviews was that of the United States. The 
frequency and percentage of occurrence of each code can be found in Table 1. Guest from this country placed great importance on service that is both accommodating and flexible (54\%), friendliness of the service providers (53\%), professionalism (41\%) and the satisfaction of needs, especially those of self-esteem (40\%). All of these codes combined paint a picture of a guest places great emphasis on the inter-personal aspects of the service experience. More so, guests from the United States assigned great value to the satisfaction of individual needs, namely through experiences that would make them feel valued, special, and treated as an individual. The most frequently mentioned department was the front office (31\%) followed by housekeeping (24\%). The top amenity desired by American guests was a superior room (26\%). Another noticeable pattern among American customers is the great value placed on complementary items, extra services, and upgrades. This in turn might be indicative of a culture that places great emphasis on value and in which sales promotion is a customary form of marketing.

\section{>>>> Insert Table $1<<<<<$}

\subsection{Northern European Guests}

During the course of the study, the researchers interviewed several European guests $(\mathrm{n}=$ 38). Most of these guests were visiting from Germany. The frequency of codes from the content analysis of these interviews can be found in Table 2. Guests from this region placed great importance on friendliness (63\%), service that is accommodating and flexible (45\%), problem resolution (42\%) and professionalism (42\%). With more accounts of problem resolution than any other cultural group, Northern Europeans seemed to: a) notice problems with rooms and service more often, and b) place great emphasis on finding practical solutions to any issues they encounter. Northern Europeans also placed more emphasis on the hotel room (37\%) than guests 
from any other region. The most cited service department was the front office (21\%) followed by restaurant service (16\%).

\section{> > > Insert Table $2<<<<<~$}

\subsection{South American Guests}

Guests from South America were also interviewed during the study. Most of the guests from this region came from the country of Brazil. Some of the most frequently mentioned codes were friendliness (63\%), professionalism (47\%), and efficiency (37\%). In fact, South Americans seemed to value efficiency more than any other group interviewed. A possible explanation for this phenomenon could be a contrast effect. North American culture has been typically characterized for their stricter adherence to deadlines, and punctuality. This in turn may be reflected in the service of the hotel, which may be outside of the norm for South American customers, who might be accustomed to a slower phase of service. A key finding of this study is that Latin American guests seemed to recall more delightful experiences regarding food and beverage. In fact, $53 \%$ of all South Americans expressed their delight with food from the hotel's restaurants, and $26 \%$ expressed delightful experiences regarding the food received at their rooms. This is more than any other cultural group studied during the present research. See Table 3 for a complete listing of the codes, frequencies, and percentages for the South American guest group.

\section{> > > > Insert Table $3<<<<<~$}

\subsection{Canadian Guests}

Canadian guests were the subject of several research interviews. Some of the most frequently mentioned codes for this group include: friendliness (79\%), professionalism (58\%), and problem resolution (42\%). Although friendliness was one of the unifying delight characteristics for the various cultural groups, Canadians seemed to be more delighted for this 
particular reason. Furthermore, Canadians recalled more delightful experiences associated with a pleasant surprise (32\%). The element of surprise has been a source of debate among customer delight scholars. Nevertheless, this research shows that some cultural groups are more likely to value service experiences that provide a positive surprise than others. This group also seemed to place the greater emphasis on room cleanliness (37\%). See Table 4 for a complete list of codes, frequencies, and percentages for Canadian hotel guests.

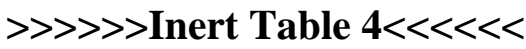

\section{Discussion and Conclusions}

Welcoming all guests is the calling shared by those who work in the hotel industry. The execution of such duty is complex in nature, as guests from different cultures appear to have different preferences and expectations from hoteliers. Guests from the United States place great emphasis on service that is flexible, fulfills their esteem needs, and that is friendly and professional. American guests also seem to emphasize the value aspect of the service experience, as they referred to complimentary amenities, upgrades, and services more than any other nationality in the present research. The results are in agreement with the work of Ma et al. (2013) which proposed that delight can be elicited when guests perceive the experience as important to their personal well-being or special needs. Furthermore, Schneider and Bowen (1999) had proposed that the satisfaction of esteem needs is important means to generate customer delight. The present study restates the importance of this factor, while at the same time suggests that the fulfillment of esteem needs might be stronger for citizens of the United States of America.

Hoteliers in the United States might be tempted to provide the same style of service that their American guests seem to enjoy, however, they will likely receive different results from 
international guests. A complementary amenity of upgrade might be the ultimate expression of a hotel's desire to please the guests from an American perspective; however it might not be such a critical delight factor to a guest from Brazil. By the same token a hotel in Brazil who receives multiple guests from the United States can learn that providing a complimentary item or upgrade, no matter how small, can go a long way towards pleasing their American guests.

Guests from Northern Europe placed great emphasis on friendliness and problem resolution. Furthermore, Northern Europeans placed more emphasis on any other cultural group on finding practical solutions to problems they experienced during their stay. They were also the most delighted with their hotel rooms. While this cultural group stressed the intangibles aspects of the service experience, they were also more prone to those aspects which emphasize practicality and utility of the hotel core product and service. In support of this, research by Hosany and Witham (2010) suggested that aesthetic elements were the key towards the creation of an experience.

Latin American guests highlighted both tangible and intangible aspects of their experience. Friendliness and professionalism were two of the top reasons for their delight with the hotel. However, they were also the cultural group that placed the more emphasis on the food. Both restaurant and room service food were of major importance to South American guests, who seemed to recall a delightful experience involving this aspect more than any other cultural group. Hotels seeking to attract this segment of travelers might do well in providing quality food offerings. An interesting finding of this research is that South Americans were delighted by the efficiency and timeliness of service. Traditionally, Latin American culture has been perceived as a culture in which deadlines and the concept of time in general tend to be more flexible. It might be that having visited hotels in North America, they notice a contrast effect when compared to 
the countries they visit from. In the previous research by Ma et al. (2013), goal congruence was suggested as a factor that elicited customer delight. Therefore, the specific goals and expectations of these particular guests with regards to friendliness, and food might lead them to highlight such aspects of the service experience more so than other international guests.

Canadian guests placed more emphasis on friendliness, cleanliness, and the element of surprise than any other cultural group. Surprise has been a contentious subject among customer delight researchers. The present research study suggests that surprise might be more present in the members of certain cultures and nationalities. The current study highlights many of the differences that exist among the various cultures. However, it is noteworthy to highlight that some aspects of service are more universal in nature. All cultural groups seemed to place great emphasis on friendliness. This particular path towards achieving customer delight is the one that is most likely to be understood by hotels, and thus the one that hotels must strive to accomplish. As hoteliers seek to expand their customer base, it is critical to know the likes and preferences of various cultural groups.

While the present study provides great insight as to the various elements that comprise customer delight from a cross-cultural perspective, it is also noteworthy to state that some limitations exist. The current study employed the technique of personal interview for data collection. While the interviews yielded substantive insights for the phenomenon of customer delight, future research can explore this topic from a quantitative perspective. This study highlights the preferences of guests from four cultural groups. However, more research can explore other cultural groups not explored in this paper. Furthermore, future research can explore other individual differences such as age and gender and their effects on customer delight. The 
present study explored one segment of the hospitality industry: upscale hotels. Future studies can research customer delight in other settings such as theme parks, events, and foodservice.

Every hotelier would like to see their guests delighted. However, what delights a guest from one culture might not delight all the other guests. In a previous study, Hofstede (1994) challenged the widespread applicability of management theories. While most studies of customer delight explore one particular culture, this particular paper contributes to the theory of customer delight by suggesting that some variations in the key drivers of customer delight exists based on the consumer's national culture. Therefore, it is important to appropriately target various guest groups and cater the service and amenity to their preferences. A series of universal factors of service, such as friendliness are likely to appeal to all guests. Therefore, it is critical that hoteliers pay attention to these above all, and then target specific changes to their service strategy and product offerings to delight guests from particular cultural groups. The calling of all those involved in the service experience is to enhance it such that guests are not only satisfied, but delighted. Scholars and practitioners constantly seek to fulfill the duty of creating a memorable experience. By understanding the effects of culture, everyone can ensure that guests- that is all guests-emerge from the hotel experience truly and completely delighted. 


\section{References}

Berman, B. 2005. How to Delight Customers. California Management Review, 48 (1), 1129-151.

Bourdieu, P. 1977. Outline of a Theory of Practice. Cambridge University Press, New York.

Bowden, J., and T. Dagger, 2011.To delight or not to delight? An investigation of loyalty formation in the restaurant industry. Journal of Hospitality Marketing and Management,. 20, (5), 501-524.

Crotts, J, and Erdmann, R. 2000. Does national culture influence consumers' evaluation of travel services? A test of Hofstede's model of cross-cultural differences. Managing Service Quality, 6, 410-419.

Crotts, J, and V. Magnini 2010. The customer delight construct: Is surprise essential? Annals of Tourism Research, 37 (4).

Crotts, J., Pan, B., and Raschind, A. 2008. A survey method for identifying key drivers of guest delight, International Journal of Contemporary Hospitality Management, 20 (4), 462470.

Ekini, Y, P. Dawes, and G. Massey, 2008. An extended model of the antecedents and consequences of consumer satisfaction for hospitality and services. European Journal of Marketing, 42 (1/2), 35-38

Finn, A. 2005. Reassessing the foundations of customer delight. Journal of Service Research, 8(2), 103-116.

Grewal, D., Levy, M., and Kumar, V. (2009). Customer Experience Management in Retailing: An Organizing Framework. Journal of Retailing, 85(1), 1-14.

Hofstede, G. 1993. Cultural constraints in management theories. Academy of Management Executive, 7 (1), 81-93. 
Hosany, S., and Witham, M. 2010. Dimensions of cruisers' experiences, satisfaction, and intention to recommend. Journal of Travel Research, 49 (3), 351-364.

Iverson, K. 2000. Managing for effective workforce diversity. Cornell Hotel and Restaurant Administration Quarterly, 41 (2), 31-39.

Keinningham, T.L., M.K. Goddard, T.G. Vavra, and A.J Laci 1999. Customer delight and the bottom line, Marketing Management, 8, (3), 57-64.

Kitayama S, Markus, H.R., Kurosawa M. 2000. Culture, emotion, and well-being: good feelings in Japan and the United States. Cognition and Emotion. 14:93-124.

Kumar, A., R.W. Olshavsky, and M.F. King 2001. Exploring the antecedents of customer delight, Journal of Consumer Satisfaction, Dissatisfaction and Complaining Behavior, $14,14-27$

Laroche, M., Ueltschy, L., Abe, S., Ceveland, M., and Yannopoulos, P. 2004. Service quality perceptions and customer satisfaction: Evaluating the role of culture. Journal of International Marketing, 12 (3), 58-85.

Luna, D., Gupta, S. 2001. An integrative framework for cross-cultural consumer behavior. International Marketing Review, 18 (1), 45-69.

Ma, J., Gao, J., Scott, N., Ding, P. (2013). Customer delight from theme park experiences: The antecedents of delight based on cognitive appraisal theory, Annals of Tourism Research, $42,359-381$.

Magnini, V., J. Crotts, and A. Zehrer 2010. Identifying drivers of customer delight through travel blog analysis, Journal of Travel Research, 49, (2), 153-164.

Markus, H. R., and Kitayama, S. 1994. The cultural construction of self and emotion: Implications for social behavior. In S. Kitayama and H. R. Markus (Eds.), Emotion and 
culture: Empirical studies of mutual influence. Washington, DC: American Psychological Association.

Oliver, R. 1980. A Cognitive model of the antecedents and consequences of satisfaction Decisions. Journal of Marketing Research, 17(4), 460-469.

Parasuraman, A., Berry, L, Zeithaml, V. (1988). SERVQUAL: A multiple-item scale for measuring consumer perceptions of service quality. Journal of retailing, 64 (1), 12-40.

Patterson, K. 1997. Delighted clients are loyal clients, Rough Notes, 140, ( 3), 221-234.

Rust, R.T., and R.L. Oliver. 2000. Should we delight the customer? Journal of the Academy of Marketing Science, 28,(1), 86-94.

Schneider, B., and D. Bowen. 1999. Understanding customer delight and outrage, Sloan Management Review, 4, (1), 35-46.

Sheth, J. N., Newman, B. I., and Gross, B. L. 1991. Consumption Values and Market Choices. Cincinnati, OH: South-Western Publishing Co.

Skogland, I., and J. Siguaw 2004. Are your satisfied customers loyal?, Cornell Hotel and Restaurant Administration Quarterly, 45, (3), 221-234.

Tsaur, S., Lin, C., Wu, C. 2005. Cultural differences of service quality and behavioral intentions in tourist hotels. Journal of Hospitality and Leisure Marketing, 13 (1), 41-63.

Torres, E. and S.F. Kline. 2006. From customer satisfaction to delight: A model for the hotel industry, International Journal of Contemporary Hospitality Management. 18 (4), 290301.

Torres, E., Kline, S. 2013. From customer satisfaction to customer delight: Creating a new standard of service for the hotel industry. International Journal of Contemporary Hospitality Management, 25 (5). 
Tylor, E. 1924. Primitive culture. $2^{\text {nd }}$ edition. New York: Brentano's.

Varey, C. and Kahneman, D. 1992. Experiences extended across time: Evaluation of moments and episodes. Journal of Behavioral Decision Making, 5 (3), 169-185.

Wang, X. 2011. The effect of unrelated supporting service quality on customer delight, satisfaction, and repurchase intentions. Journal of Service Research, 14, (2), 149-163.

Weiermair, K. 2000. Tourists' perceptions towards and satisfaction with service quality in the cross-cultural service encounter: Implications for hospitality and tourism management. Managing Service Quality, 10 (6), 397-409. 


\section{Appendix A - Customer Delight Interview Protocol}

\section{Customer delight interview protocol}

Country of Origin - Where are you visiting from?

1) Which service/amenity were you using when you had the delightful experience that you can describe to me?

2) Could you please describe the circumstances leading up to the delightful experience?

What happened during the experience? What specific details do you recall that made this experience particularly memorable and positive for you?

3) How many times before this delightful experience had you stayed/visited this..?

4) Was there a moment when the hotel staff acknowledged and fulfilled your needs? Please describe briefly

5) Was there a moment when the hotel solved a problem with the stay? Describe.

6) Was there a situation where you experienced an outstanding level of professionalism from the staff? Please describe briefly.

7) Where you surprised during your experience? Why or why not?

Please indicate your agreement with the following statements (Behavioral intentions) on a 1-7 scale, where 1 is strongly disagree and 7 is strongly agree

8) Would you stay/visit again in the future? 1234567

9) Would you spread positive things to others about this experience? 1234567

10) Would you recommend this ...to others? 1234567 


\section{Appendix B - Codebook}

$\underline{\text { Product Mix and Amenities }}$

1- Room

2- Lobby

3- Pool and Leisure Facilities

4- Facilities - gym, and other public spaces

5- Overall superior facilities

22- Amenities - other

23- Complementary amenities / upgrades / services

$\underline{\text { Service }}$

6- Surprise

7- Friendliness

8- Problem Resolution

9- Professionalism

10- Needs Satisfied

11- Accommodating / Flexible

12- Personalized Service

13-Efficiency / Timeliness

$\underline{\text { Service Department or Divisions }}$

14- Front Office

15- Housekeeping / Cleanliness

16- Room Service - culinary

17- Room service - service 
18- Restaurants and lounges - culinary

19- Restaurants and lounges - service

20- Guest Services (i.e. concierge, bell staff, etc.)

21-Banquets

22- Amenities - others 